\title{
Chest wall kinematics and respiratory muscle action in ankylosing spondylitis patients
}

\author{
I. Romagnoli*, F. Gigliotti*, A. Galarducci*,\#, B. Lanini*, R. Bianchi*, D. Cammelli\#, G. Scano*,\#
}

Chest wall kinematics and respiratory muscle action in ankylosing spondylitis patients. I. Romagnoli, F. Gigliotti, A. Galarducci, B. Lanini, R. Bianchi, D. Cammelli, G. Scano. (C) ERS Journals Ltd 2004.

ABSTRACT: No direct measurements of the pressures produced by the ribcage muscles, the diaphragm and the abdominal muscles during hyperventilation have been reported in patients with ankylosing spondylitis. Based on recent evidence indicating that abdominal muscles are important contributors to stimulation of ventilation, it was hypothesised that, in ankylosing spondylitis patients with limited ribcage expansion, a respiratory centre strategy to help the diaphragm function may involve coordinated action of this muscle with abdominal muscles.

In order to validate this hypothesis, the chest wall response to a hypercapnic/hyperoxic rebreathing test was assessed in six ankylosing spondylitis patients and seven controls by combined analysis of: 1) chest wall kinematics, using optoelectronic plethysmography, this system is accurate in partitioning chest wall expansion into the contributions of the ribcage and the abdomen; and 2) respiratory muscle pressures, oesophageal, gastric and transdiaphragmatic $(P \mathrm{di})$; the pressure/volume relaxation characteristics of both the ribcage and the abdomen allowed assessment of the peak pressure of both inspiratory and expiratory ribcage muscles, and of the abdominal muscles.

During rebreathing, chest wall expansion increased to a similar extent in patients to that in controls; however, the abdominal component increased more and the ribcage component less in patients. Peak inspiratory ribcage, but not abdominal, muscle pressure was significantly lower in patients than in controls. End-inspiratory $P_{\mathrm{di}}$ increased similarly in both groups, whereas inspiratory swings in $P_{\text {di }}$ increased significantly only in patients. No pressure or volume signals correlated with disease severity.

The diaphragm and abdominal muscles help to expand the chest wall in ankylosing spondylitis patients, regardless of the severity of their disease. This finding supports the starting hypothesis that a coordinated response of respiratory muscle activity optimises the efficiency of the thoracoabdominal compartment in conditions of limited ribcage expansion.

Eur Respir J 2004; 24: 453-460.
*Don C. Gnocchi Foundation, Section of Respiratory Rehabilitation, Pozzolatico, and ${ }^{\#}$ Dept of Internal Medicine, University of Florence, Florence, Italy.

Correspondence: G. Scano

Dipartimento di Medicina Interna

Università di Firenze

Viale G.B. Morgagni, 85

50134 Firenze

Italy

Fax: 39055412867

E-mail: g.scano@dmi.unifi.it

Keywords: Ankylosing spondylitis chest wall kinematics respiratory muscles

Received: November 52003

Accepted after revision: April 52004
The pathological process of ankylosing spondylitis may involve fusion of costovertebral and sternoclavicular joints, along with intercostal muscle atrophy [1], resulting in limited motion of the chest wall [2-5]. With the reduction in expansion of the ribcage, ventilation becomes increasingly dependent on the diaphragm, which largely compensates for ribcage immobility during hyperventilation $[4,6]$. To the best of the present authors' knowledge, no data have been reported on direct measurements of the pressures produced by the ribcage muscles $(P \mathrm{M}, \mathrm{rc})$, diaphragm and abdominal muscles $(P \mathrm{M}, \mathrm{Abd})$ during hyperventilation in patients with ankylosing spondylitis.

Recent evidence indicates that the abdominal muscles are important contributors to ventilation in healthy humans [7-11]. The gradual inspiratory relaxation of the abdominal muscles during induced hyperventilation helps substantially increase the volume of the chest wall $(V \mathrm{cw})$ and lets the diaphragm act as a flow generator $[8,9,11]$. Therefore, it was hypothesised that, in patients with ankylosing spondylitis and limited ribcage expansion, a respiratory centre strategy to help the diaphragm function may involve the coordinated action of the diaphragm and abdominal muscles. In order to validate this hypothesis in six ankylosing spondylitis patients, the ventilatory response to carbon dioxide was assessed by combined analysis of respiratory muscle pressures and chest wall kinematics using optoelectronic plethysmography (OEP). OEP measures breathing without a mouthpiece and noseclip by accurately quantifying the change in volume of any chest wall compartment (e.g. ribcage and abdomen) $[8,9,11]$.

\section{Methods}

\section{Subjects}

The six patients studied were affected by ankylosing spondylitis according to the modified New York criteria [12]. Seven healthy subjects matched for sex, age and height were studied as control. Based on the evaluation of disease activity index (Bath Ankylosing Spondylitis Disease Activity Index), functional index (Bath Ankylosing Spondylitis Functional Index) and radiological index (Bath Ankylosing Spondylitis Radiological Index) [13], patients exhibited varying degrees of disease severity: mild (minimal limitation of chest expansion 
and sacroiliitis (patients 2 and 6)), severe (low back pain, limited motion of lumbar spine, limited chest expansion and sacroiliitis (patients 1,3 and 5)) and intermediate (patient 4). High-resolution computed tomography excluded lung parenchymal involvement. All subjects were nonsmokers, free of cardiopulmonary disorders and experienced in performing respiratory manoeuvres. Written informed consent, obtained after a description of the protocol, was approved by the Ethics Committees of the Don C. Gnocchi Foundation (Pozzolatico, Italy) and the University of Florence (Florence, Italy).

\section{Spirometry}

Routine spirometry, with the patients seated in a comfortable armchair, was performed as previously described [14]. Functional residual capacity was measured by the heliumdilution technique. The normal values for lung volumes were those of the European Coal and Steel Community [15].

\section{Compartmental volume measurements}

The volumes of the different chest wall compartments were assessed using the OEP system (fig. 1). Details of this technique have been reported elsewhere $[8,9,11,16]$. In brief, this system permits computation of the three-dimensional coordinates of 89 surface markers applied to the chest wall surface with high accuracy [16]. The markers, small hemispheres ( $5 \mathrm{~mm}$ in diameter) coated with reflective paper, were placed circumferentially in seven horizontal rows between the clavicles and the anterior superior iliac spine. Along the horizontal rows, the markers were arranged anteriorly and posteriorly in five vertical columns, and there was an additional bilateral column in the midaxillary line. The marker configuration proposed by CALA et al. [16] was used to improve volume accuracy and to define anatomically three specific chest wall compartments: the pulmonary ribcage, i.e. the rib cage apposed to the lung; the abdominal ribcage, i.e. the ribcage apposed to the diaphragm; and the abdomen, as proposed by WARD et al. [17]. The boundary between the pulmonary and abdominal ribcage was assumed to be at the xiphoid level, and the boundary between the abdominal ribcage and the abdominal compartment was along the lower costal margin anteriorly, and at the level of the lowest point of the lower costal margin posteriorly. The coordinates of the markers
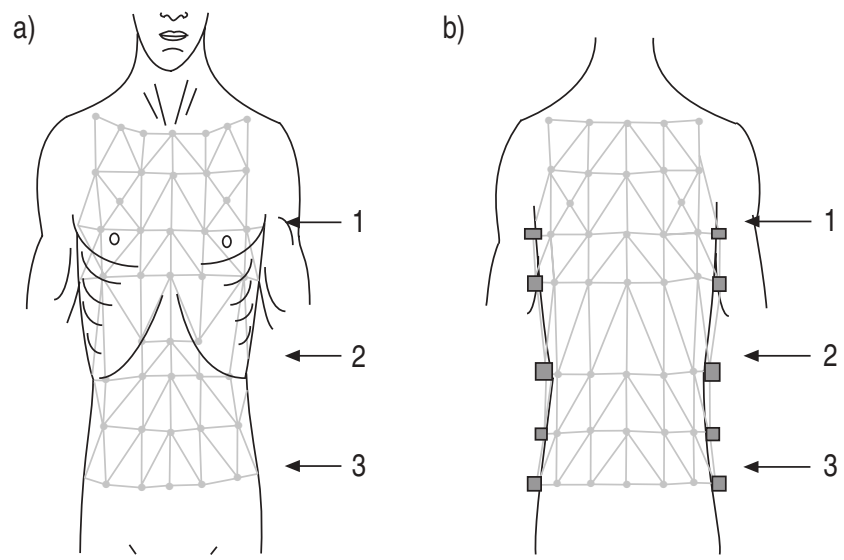

Fig. 1.-Three-compartment chest wall model: a) anterior view, and b) posterior view (1: lung-apposed ribcage; 2: diaphragm-apposed ribcage; 3: abdomen). The compartmental limits are described in the Compartmental volume measurements section. were evaluated using a system configuration of four television cameras (two in front of and two behind the subject) at a sampling frequency of $50 \mathrm{~Hz}$. Starting from the marker coordinates, the thoracoabdominal volumes were computed by surface triangulation. The $V \mathrm{cw}$ was modelled as the sum of ribcage volume $(V \mathrm{rc})$ and abdominal volume $(V \mathrm{Abd})$. $V \mathrm{rc}$ was modelled as the sum of the volumes of the pulmonary ( $V$ rc,pulm) and abdominal $(V \mathrm{rc}, \mathrm{Abd})$ ribcage; ventilation $\left(V^{\prime} \mathrm{E}\right)$ was calculated from the OEP tidal volume $(V \mathrm{~T})(V \mathrm{~T}, \mathrm{OEP})$ and the respiratory frequency $(f R)$. $V T$ was simultaneously measured using a water sealed spirometer $(V \mathrm{~T}, \mathrm{sp})$. The volume accuracy of the OEP system was tested by comparing $V \mathrm{~T}$, OEP to $V \mathrm{~T}$,sp.

\section{Pressure measurements}

Oesophageal $(P$ oes $)$ and gastric $(P$ ga $)$ pressures were measured using a conventional balloon catheter system connected to two $100-\mathrm{cmH}_{2} \mathrm{O}$ differential pressure transducers (Validyne Corp., Northridge, CA, USA). Poes was used as an index of pleural pressure and $P$ ga of abdominal pressure. From the pressure signals, $P$ oes and $P$ ga were measured at end-inspiration and end-expiration at zero flow points. The transdiaphragmatic pressure $(P \mathrm{di})$ was obtained by subtracting $P_{\mathrm{oes}}$ from $P$ ga. $P$ di at end-expiration during quiet breathing $(\mathrm{QB})$ was assumed to be zero. Change in $P$ di was measured from the beginning to the end of inspiration $[8,9,18,19]$. Pressure and flow signals were recorded on to an IBM-compatible personal computer using an RTI 800 analogue-to-digital card, synchronised to the chest wall kinematic data from the OEP system and used to compute volume changes.

\section{Ribcage and abdomen relaxation measurements}

The relaxation characteristics of the chest were studied at rest with the subject breathing room air. Subjects, in a sitting position, inhaled to total lung capacity (TLC) and then relaxed and exhaled through a high resistance to functional residual capacity (FRC). Relaxation manoeuvres were repeated until curves were reproducible, pressure at the mouth returned to zero and $P$ di was zero throughout the entire manoeuvre.

In order to assess ribcage relaxation characteristics, $V$ rc,pulm was plotted against $P$ oes. The best fitting linear regression ( $V \mathrm{rc}$,pulm $=b+a P$ oes $)$ of the $V \mathrm{rc}$,pulm $/ P_{\text {oes }}$ curve was retained to construct relaxation curves. The relaxation curve of the abdomen was obtained by plotting $P$ ga against $V$ Abd from end-expiratory ( $V$ Abd,EE) to end-inspiratory ( $V$ Abd,EI) $V$ Abd during QB; a curvilinear relationship was found, which fitted a second-order polynomial regression $[8,9]$. This was extrapolated linearly from high and lower VAbd. In two patients, it was not possible to define an abdominal relaxation line because of the presence of a figure-of-eight pattern $V \mathrm{Abd} / P$ ga loop during QB. Displacements of dynamic pressure/volume curves downwards and to the right of these relationships were taken as evidence of abdominal muscle recruitment.

\section{Respiratory muscle pressure measurements}

The pressures developed by inspiratory $(P \mathrm{M}, \mathrm{rc}, \mathrm{I})$ and expiratory $(P \mathrm{M}, \mathrm{rc}, \mathrm{E})$ ribcage muscles were measured as the horizontal distance along the pressure axis between the dynamic $P_{\text {oes }} / V \mathrm{rc}$,pulm loops and the relaxation pressure/ volume curve of the pulmonary ribcage. The $P$ M,Abd was measured as the horizontal distance along the pressure axis between the dynamic $P$ ga/ $V$ Abd loops and the relaxation pressure/volume curve of the abdomen $[8,9,11]$. The graphic 
methods for measuring $P$ M,rc and $P$ M,Abd provide information about integration of kinematic and pressure data (fig. 2).

\section{Hyperoxiclhypercapnic rebreathing test}

The rebreathing method of READ [20] was used to measure the hypercapnic/hyperoxic ventilatory response. After a 10min adaptation period, the subject, breathing through a mouthpiece, underwent the rebreathing test. A gas mixture (7\% $\mathrm{CO}_{2} / 93 \%$ oxygen) was inhaled for $5 \mathrm{~min}$ from a $6-\mathrm{L}$ rebreathing balloon. Expired carbon dioxide tension $\left(\mathrm{PCO}_{2}\right)$ was monitored continuously at the mouth using an infrared $\mathrm{CO}_{2}$ meter (Datex Normocap 200; Datex Instrumentarium Corp., Helsinki, Finland). Details have been described elsewhere [21]. The test was terminated when end-tidal $\mathrm{PCO}_{2}$ reached $9.3-9.6 \mathrm{kPa}(70-72 \mathrm{mmHg})$.
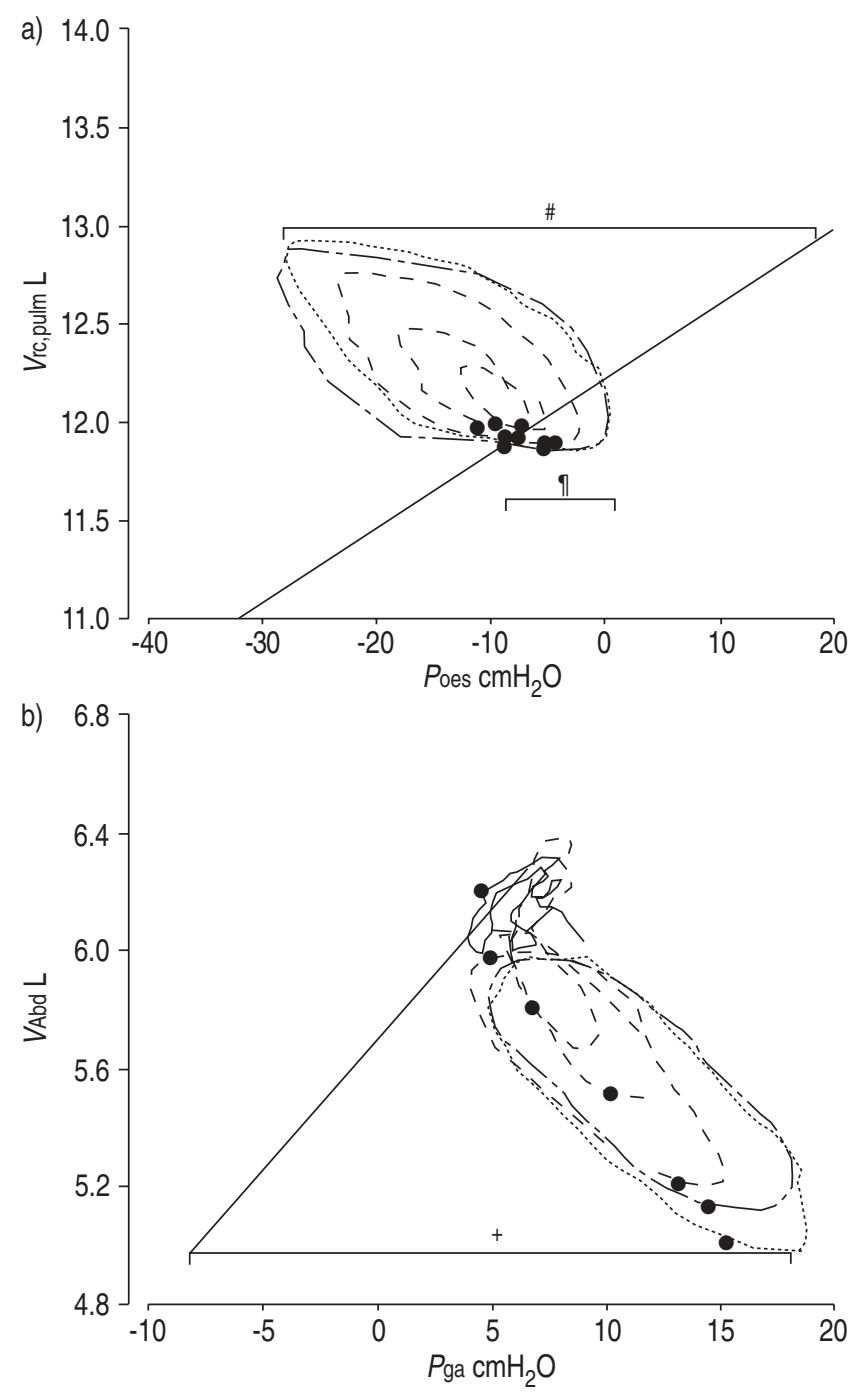

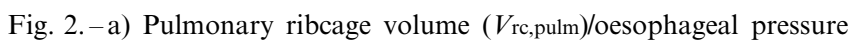
$\left(P_{\text {oes }}\right)$; and b) abdominal volume (VAbd)/gastric pressure ( $\left.P_{\text {ga }}\right)$ dynamic loops in a representative control subject during quiet breathing and at increasing expired carbon dioxide tensions. Horizontal bars indicate distances between peak $P_{\text {oes }} / P_{\mathrm{ga}}$ and the relaxation line $(\longrightarrow)$ at the same volume (@: end-expiratory lung volume). \#: pressure developed by inspiratory ribcage muscles; ${ }^{\uparrow}$ : pressure developed by expiratory ribcage muscles; ${ }^{+}$: pressure developed by abdominal muscles.

\section{Protocol}

Experimental data were obtained from all subjects at rest in a sitting position while breathing room air (QB) for 6-10 min and during the rebreathing test. Variables were recorded continuously and calculated at the end of each of a 30 -s period to obtain the mean of six respiratory cycles. The rebreathing test was repeated twice 30-45 min apart and the collected data were averaged.

\section{Data analysis}

The results from all respiratory cycles at rest and during the rebreathing test were pooled for each subject. The limits of agreement between $V \mathrm{~T}$, OEP and $V \mathrm{~T}$,sp were evaluated by Bland and Altman analysis [22]. In order to assess $P$ M,rc, changes in Poes were plotted against changes in $V$ rc,pulm. The slopes of the $V \mathrm{rc}$,pulm/Poes relaxation line were calculated, in each subject, by single regression analysis. Since the plot of $V \mathrm{Abd} / P$ ga during relaxation was curvilinear, this curve was manually fitted to pressure/volume data. Two-way analysis of variance and Bonferroni's test were performed to compare each set of data obtained breathing room air and during hypercapnic rebreathing. Pearson's linear regression analysis was performed between $\mathrm{PCO}_{2}$, as independent variable, and pressures and volumes, as dependent variables. All data are presented as mean \pm SEM unless otherwise indicated. A p-value of $<0.05$ was considered significant.

\section{Results}

The anthropometric and clinical data of patients and controls are shown in table 1 . In patient 1, vital capacity, TLC and forced expiratory volume in one second were lower than predicted, whereas, in patients 3 and 6 , FRC was mildly reduced. Compared with controls, patients exhibited: 1) a greater $V^{\prime} \mathrm{E}(\mathrm{p}<0.00002)$ and $f \mathrm{R}(\mathrm{p}<0.005)$ during $\mathrm{QB}$, and lesser-fold increases at a $P \mathrm{CO}_{2}$ of $9.3 \mathrm{kPa}(70 \mathrm{mmHg})(\mathrm{p}<0.001$ and $\mathrm{p}<0.03$, respectively); 2) a greater duty cycle during QB $(\mathrm{p}<0.05)$ with no significant changes, unlike controls $(\mathrm{p}<0.02)$, at a $P \mathrm{CO}_{2}$ of $9.3 \mathrm{kPa}$; and 3$)$ similar $V \mathrm{~T} /$ inspiratory time during $\mathrm{QB}$, with less increase at a $\mathrm{PCO}_{2}$ of $9.3 \mathrm{kPa}$ $(\mathrm{p}<0.02)$.

\section{Chest wall volumes}

During rebreathing, in patients and controls, end-inspiratory $V_{\text {cw }}(V$ cw,EI $)$ progressively increased $(\mathrm{p}<0.03$ and $\mathrm{p}<0.00001$, respectively) and end-expiratory $V_{\mathrm{cw}}\left(V_{\mathrm{cw}}, \mathrm{EE}\right)$ progressively decreased ( $p<0.001$ for both) (fig. 3). The progressive increase in end-inspiratory $V \mathrm{rc}(V \mathrm{rc}, \mathrm{EI}) \quad(\mathrm{p}<0.009$ and $\mathrm{p}<0.00001$, respectively) was due to the increase in both end-inspiratory $V$ rc,pulm $(\mathrm{p}<0.004$ and $\mathrm{p}<0.00001$, respectively) and endinspiratory $V \mathrm{rc}, \mathrm{Abd}(\mathrm{p}<0.02$ and $\mathrm{p}<0.00001$, respectively). $V$ Abd,EI $(\mathrm{p}<0.0001)$ increased only in patients. In neither group did end-expiratory $\operatorname{Vrc}(\mathrm{p}>0.05$ for both) change significantly; thus the decrease in $V \mathrm{cw}, \mathrm{EE}$ was, in both groups, entirely due to the progressive reduction in $V \mathrm{Abd}, \mathrm{EE}$ $(\mathrm{p}<0.001$ for both).

Compared to controls, the change in $V \mathrm{rc}, \mathrm{EI} / \mathrm{PCO}_{2}$ was significantly lower $(0.039 \pm 0.015$ and $0.012 \pm 0.008$, respectively, $\mathrm{p}<0.002$ ), whereas the change in $V \mathrm{Abd}, \mathrm{EI} / \mathrm{PCO}_{2}$ was significantly higher $(0.010 \pm 0.006$ and $0.023 \pm 0.014, \mathrm{p}<0.04)$ in patients.

During QB and at a $\mathrm{PCO}_{2}$ of $9.3 \mathrm{kPa}(70 \mathrm{mmHg})$ : 1) chest 
Table 1.-Anthropometric, clinical and functional data of patients and controls

\begin{tabular}{|c|c|c|c|c|c|c|c|c|c|c|c|}
\hline $\begin{array}{l}\text { Subject } \\
\text { No. }\end{array}$ & $\begin{array}{l}\text { Age } \\
\text { yrs }\end{array}$ & $\begin{array}{c}\mathrm{BMI} \\
\mathrm{kg} \cdot \mathrm{m}^{-2}\end{array}$ & $\begin{array}{l}\text { BASFI } \\
\text { score }\end{array}$ & $\begin{array}{l}\text { BASDAI } \\
\text { score }\end{array}$ & $\begin{array}{l}\text { BASRI } \\
\text { score }\end{array}$ & $\begin{array}{c}\text { Disease } \\
\text { duration yrs }\end{array}$ & $\begin{array}{l}\mathrm{VC} \mathrm{L} \\
\% \text { pred }\end{array}$ & $\begin{array}{l}\text { FRC L } \\
\% \text { pred }\end{array}$ & $\begin{array}{l}\text { TLC L } \\
\% \text { pred }\end{array}$ & $\begin{array}{l}\text { FEV1 L } \\
\% \text { pred }\end{array}$ & $\begin{array}{c}\text { FEV1/VC } \\
\% \text { pred }\end{array}$ \\
\hline \multicolumn{12}{|l|}{ Patients } \\
\hline 1 & 25 & 25.0 & 410 & 390 & 4 & 7 & $3.07(56)$ & $3.05(92)$ & $5.01(70)$ & $2.82(64)$ & 92 \\
\hline 2 & 70 & 36.0 & 290 & 270 & 3 & 10 & $4.18(99)$ & $3.50(94)$ & $6.90(97)$ & 3.08 (99) & 94 \\
\hline 3 & 50 & 29.7 & 510 & 435 & 4 & 15 & $3.33(90)$ & $2.30(76)$ & $5.21(91)$ & $2.77(94)$ & 76 \\
\hline 4 & 44 & 24.3 & 535 & 445 & 1 & 10 & 5.05 (107) & $3.20(92)$ & $5.50(98)$ & $4.15(110)$ & 82 \\
\hline 5 & 51 & 24.8 & 35 & 160 & 4 & 15 & $4.55(96)$ & 4.04 (115) & $6.67(94)$ & $3.46(95)$ & 115 \\
\hline 6 & 36 & 29.7 & 25 & 130 & 2 & 10 & $4.05(90)$ & $2.28(74)$ & $5.94(102)$ & 3.34 (94) & 74 \\
\hline Mean & 46.0 & 27.9 & 301 & 305 & 3.0 & 11.2 & $4.04(89.7)$ & $3.03(90.2)$ & $5.95(90.8)$ & $3.27(92.7)$ & 90.2 \\
\hline $\mathrm{SD}$ & 15.2 & 5.0 & 227 & 139 & 1.3 & 3.2 & $0.74(17.7)$ & $0.76(16.6)$ & $0.84(12.3)$ & $0.51(15.3)$ & 16.6 \\
\hline \multicolumn{12}{|l|}{ Controls } \\
\hline Mean & 35.4 & 24.8 & & & & & $5.21(98.8)$ & $3.5(101.3)$ & 7.58 (104.9) & $4.32(103.2)$ & 101.3 \\
\hline SD & 8.7 & 2.1 & & & & & $0.64(7.2)$ & $0.2(3.9)$ & $0.70(7.7)$ & $0.80(12.4)$ & 3.9 \\
\hline
\end{tabular}

BMI: body mass index; BASFI: Bath Ankylosing Spondylitis Functional Index; BASDAI: Bath Ankylosing Spondylitis Disease Activity Index; BASRI: Bath Ankylosing Spondylitis Radiological Index; VC: vital capacity; FRC: functional residual capacity; TLC: total lung capacity; FEV1: forced expiratory volume in one second.

wall expansion/ $V \mathrm{~T}(V \mathrm{~T}, \mathrm{cw})$ was similar in patients and controls, but manifold increases at a $P \mathrm{CO}_{2}$ of $9.3 \mathrm{kPa}$ were significantly lower in patients $(\mathrm{p}<0.02)$; and 2$)$ ribcage expansion $(\%$ $V \mathrm{~T}, \mathrm{cw})$ was lower $(\mathrm{p}<0.03$ and $\mathrm{p}<0.00003$, respectively) and abdominal expansion $(\% V \mathrm{~T}, \mathrm{cw})$ higher in patients $(\mathrm{p}<0.03$ and $\mathrm{p}<0.0002$, respectively). Furthermore, in both groups, both ribcage and abdominal expansion contributed similarly to $V$ T,cw during $\mathrm{QB}$ and at a $P \mathrm{CO}_{2}$ of $9.3 \mathrm{kPa}$ (table 2).
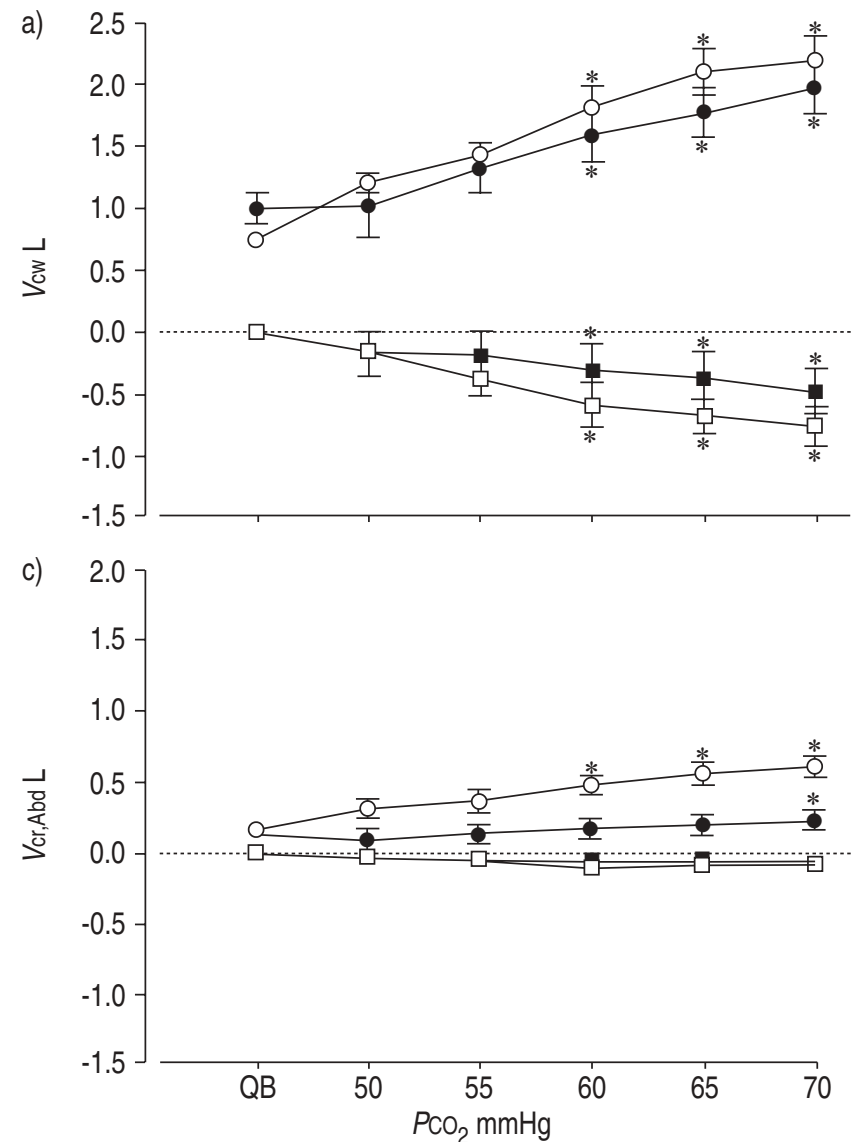

\section{Pressurelvolume loops}

Figure 2 shows $V$ rc,pulm/Poes and $V$ Abd/Pga dynamic loops in a representative control subject. On the ribcage side, $V$ rc,pulm/Poes loops (fig. 2a) show progressive inspiratory ribcage muscle recruitment with increasing $\mathrm{PCO}_{2}$; the dynamic loops cross the relaxation lines (diagonal lines), indicating recruitment of ribcage expiratory muscles throughout
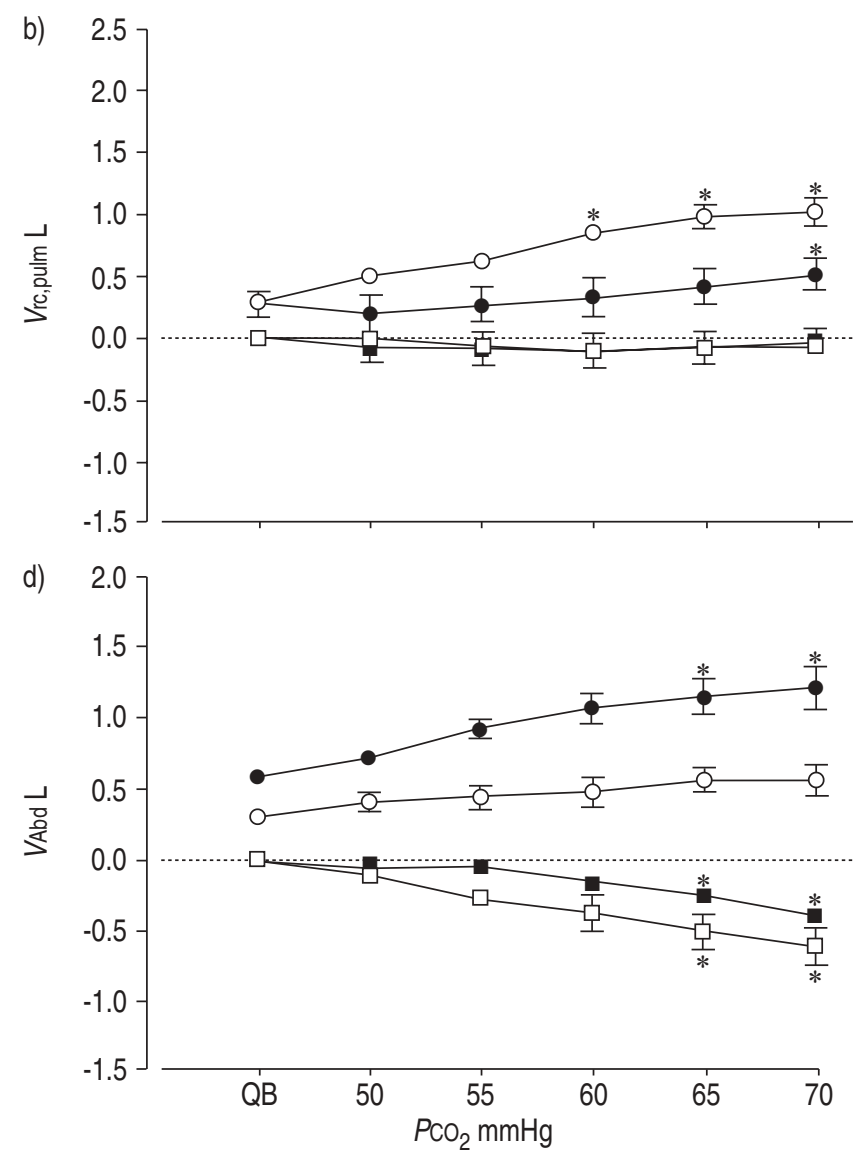

Fig. 3.-End-inspiratory ( $\bigcirc$; $\mathbf{0})$ and end-expiratory $(\square$; $\mathbf{\square})$ : a) chest wall volume $\left(V_{\text {cw }}\right)$; b) pulmonary ribcage volume $\left(V_{\text {rc,pulm) }}\right.$; c) abdominal ribcage volume $\left(V_{\mathrm{rc}, \mathrm{Abd}}\right)$; and d) abdominal volume $\left(V_{\mathrm{Abd}}\right)$ in controls $(\bigcirc ; \square)$ and patients $(\boldsymbol{O}$; $\mathbf{\square})$ during quiet breathing $(\mathrm{QB})$ and at different expired carbon dioxide tensions $\left(\mathrm{PCO}_{2}\right)$. Data are presented as mean \pm SEM. The vertical distance between the two values is the tidal volume $(\cdots$ : end-expiratory volume, set to zero, during room air breathing). *: $\mathrm{p}<0.05$ versus end-expiratory/end-inspiratory volume in same group during QB. $1 \mathrm{mmHg}=0.133 \mathrm{kPa}$. 
Table 2. - Breathing pattern during quiet breathing (QB) and at an end-tidal carbon dioxide tension of $70 \mathrm{mmHg}$ in patients and controls

\begin{tabular}{|c|c|c|c|c|c|c|c|c|c|c|c|c|c|c|}
\hline \multirow[t]{2}{*}{ Subject No. } & \multicolumn{2}{|c|}{$V^{\prime} \mathrm{E} \mathrm{L} \cdot \mathrm{min}^{-1}$} & \multicolumn{2}{|c|}{$f \mathrm{R}$ breaths $\cdot \min ^{-1}$} & \multicolumn{2}{|c|}{$V \mathrm{~T} / t \mathrm{I} \mathrm{L}^{-} \mathrm{s}^{-1}$} & \multicolumn{2}{|r|}{$t \mathrm{I} / t$ tot } & \multicolumn{2}{|c|}{$V \mathrm{~T}, \mathrm{CW} \mathrm{L}$} & \multicolumn{2}{|c|}{$V \mathrm{~T}, \mathrm{rc} \% V \mathrm{~T}, \mathrm{cw}$} & \multicolumn{2}{|c|}{$V \mathrm{~T}, \mathrm{Abd} \% V \mathrm{~T}, \mathrm{cw}$} \\
\hline & QB & $70 \mathrm{mmHg}$ & QB & $70 \mathrm{mmHg}$ & QB & $70 \mathrm{mmHg}$ & QB & $70 \mathrm{mmHg}$ & QB & $70 \mathrm{mmHg}$ & QB & $70 \mathrm{mmHg}$ & QB & $70 \mathrm{mmHg}$ \\
\hline \multicolumn{15}{|l|}{ Patients } \\
\hline 1 & 15.7 & 37.5 & 18 & 25 & 0.6 & 1.5 & 0.4 & 0.4 & 0.9 & 1.5 & 11.6 & 15.8 & 88.3 & 84.2 \\
\hline 2 & 14.9 & 66.0 & 19 & 26 & 0.6 & 2.3 & 0.5 & 0.5 & 0.8 & 2.5 & 39.6 & 44.2 & 60.4 & 55.8 \\
\hline 3 & 11.2 & 43.3 & 17 & 22 & 0.4 & 1.6 & 0.5 & 0.4 & 0.7 & 1.9 & 20.3 & 26.1 & 79.7 & 74.1 \\
\hline 4 & 15.8 & 66.9 & 18 & 29 & 0.4 & 1.1 & 0.6 & 0.4 & 0.9 & 2.3 & 64.5 & 37.2 & 35.5 & 62.9 \\
\hline 5 & 15.3 & 60.5 & 15 & 23 & 0.6 & 2.3 & 0.4 & 0.5 & 1.0 & 2.7 & 20.4 & 25.3 & 79.6 & 74.6 \\
\hline 6 & 17.4 & 55.5 & 17 & 15 & 0.7 & 2.8 & 0.4 & 0.5 & 1.0 & 3.7 & 50.0 & 31.3 & 50.0 & 68.8 \\
\hline Mean & 15.1 & $55.0(3.7)$ & 17.4 & $23.3(1.4)$ & 0.5 & $1.94(3.5)$ & 0.5 & $0.4(1)$ & 0.9 & $2.5(2.7)$ & 34.4 & 30.0 & 65.6 & 70.1 \\
\hline SD & 2.1 & $12.1(0.8)$ & 1.1 & $4.8(0.3)$ & 0.1 & $0.6(0.8)$ & 0.07 & $0.05(0.2)$ & 0.1 & $0.8(0.8)$ & 20.4 & 9.9 & 20.4 & 9.9 \\
\hline \multicolumn{15}{|c|}{ 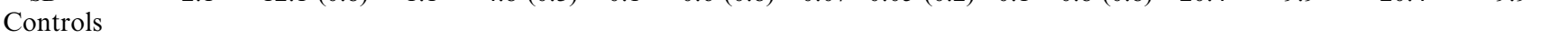 } \\
\hline Mean & 8.9 & $63.2(7)$ & 12.0 & $26.0(2.2)$ & 0.4 & $2.2(5.6)$ & 0.4 & $0.5(1.2)$ & 0.7 & $2.9(4.1)$ & 59.3 & 61.4 & 40.9 & 38.6 \\
\hline SD & 1.0 & $19.2(1.1)$ & 3.0 & $7.8(1)$ & 0.04 & $0.3(1.1)$ & 0.03 & $0.03(0.4)$ & 0.1 & $0.8(1)$ & 16.2 & 8.0 & 16.5 & 8.0 \\
\hline p-value & 0.00002 & NS & 0.005 & NS & NS & NS & 0.05 & NS & NS & NS & 0.03 & 0.00003 & 0.03 & 0.0002 \\
\hline
\end{tabular}

Manifold increases are given in parenthesis. $V^{\prime} \mathrm{E}$ : minute ventilation; $f \mathrm{R}$ : respiratory frequency; $V \mathrm{~T}$ : tidal volume; $t \mathrm{I}:$ inspiratory time; $V \mathrm{~T} / t \mathrm{I}:$ mean inspiratory flow; $t$ tot: duration of total breathing cycle; $t \mathrm{t} / t$ tot: duty cycle; $V \mathrm{~T}$,cw: chest wall expansion/tidal volume; $V \mathrm{~T}$,rc: ribcage expansion; $V \mathrm{~T}$,Abd: abdominal expansion. NS: nonsignificant. $1 \mathrm{mmHg}=0.133 \mathrm{kPa}$.

rebreathing. On the abdominal side, during $\mathrm{QB}, V \mathrm{Abd} / P$ ga loops show a positive slope during inspiration (fig. 2b): increases in $P$ ga and $V$ Abd indicate that the shortening and inspiratory descent of the diaphragm displace the abdomen along its relaxation configuration. During rebreathing, expiratory changes in $P$ M,Abd (increase) and $V$ Abd (decrease) indicate active contraction of the expiratory abdominal muscles; gradual inspiratory changes in $P$ ga (decrease) and $V$ Abd (increase) are also evident.

\section{Respiratory peak pressures}

In controls, $P$ M,rc,I, $P$ M,rc,E and $P$ M,Abd increased during hypercapnic rebreathing $(\mathrm{p}<0.00001$ for all). In patients, $P$ M,rc, I $(\mathrm{p}<0.05)$ increased significantly, but to a lesser extent, whereas $P$ M,rc,E did not increase (fig. 4); $P$ M,Abd increased progressively in three of four patients, and, in one, it increased from QB to a $\mathrm{PCO}_{2}$ of $6.7 \mathrm{kPa}(50 \mathrm{mmHg})$ and then plateaued (fig. 5). Changes in $P$ di at end-inspiration were similar in the two groups $(\mathrm{p}<0.00001)$, and, in contrast, $P$ di swing increased significantly in patients $(\mathrm{p}<0.03)$, but not in controls $(\mathrm{p}>0.05)$, in whom it tended to plateau at a $\mathrm{PCO}_{2}$ of $8.0-9.3 \mathrm{kPa}$ (60-70 mmHg) (fig. 6).

Finally, no significant relationships were found between radiological, clinical or functional scores on the one hand and $V \mathrm{rc}$ or respiratory muscle pressures on the other.

\section{Discussion}

In the present study, it was shown that the reduced expansion of the ribcage is associated with reduced $P$ M,rc in patients with ankylosing spondylitis. The diaphragm and, to a lesser extent, the abdominal muscles contribute to expansion of the chest wall regardless of the severity of the disease.

\section{Critique of model and methods}

Criticism of the present model and methods has been carried out extensively in three recent articles [8, 9, 11]. As regards the present study, direct and simple precise information about activation of the respiratory muscles could have been obtained by electromyography. However, the use of pressure signals to assess respiratory muscle activity has been shown to be as good as electromyography [23]. It is also worth noting that the present study was devised to assess how

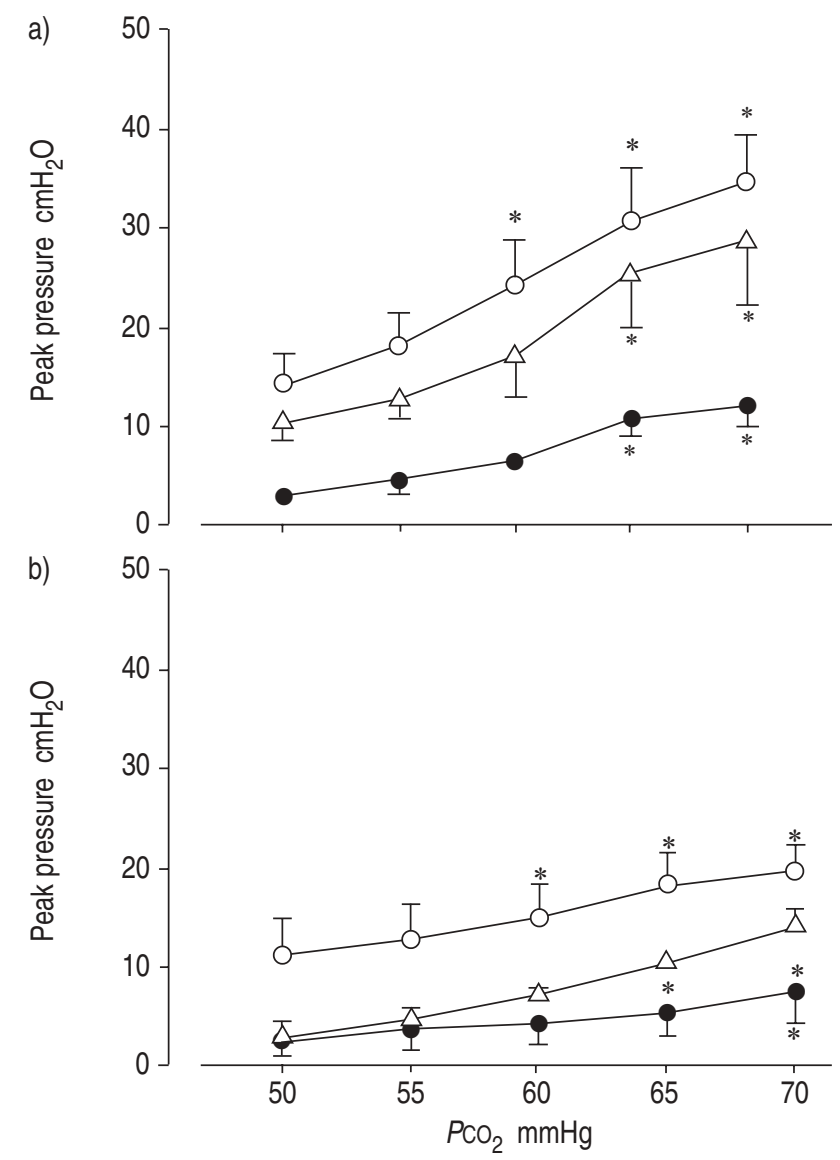

Fig. 4.-Peak respiratory muscle pressures in: a) controls; and b) patients at increasing expired carbon dioxide tensions $\left(\mathrm{PCO}_{2}\right)(\mathrm{O}$ : inspiratory ribcage muscle pressure; 0 : expiratory ribcage muscle pressure; $\triangle$ : abdominal muscle pressure). Data are presented as mean \pm SEM. *: $\mathrm{p}<0.05$ versus peak pressure in same group during quiet breathing. $1 \mathrm{mmHg}=0.133 \mathrm{kPa}$. 


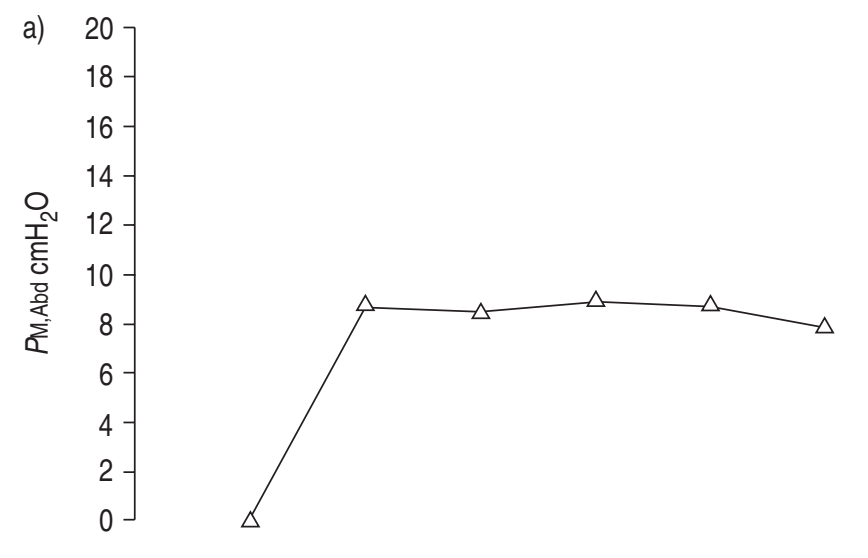

b)
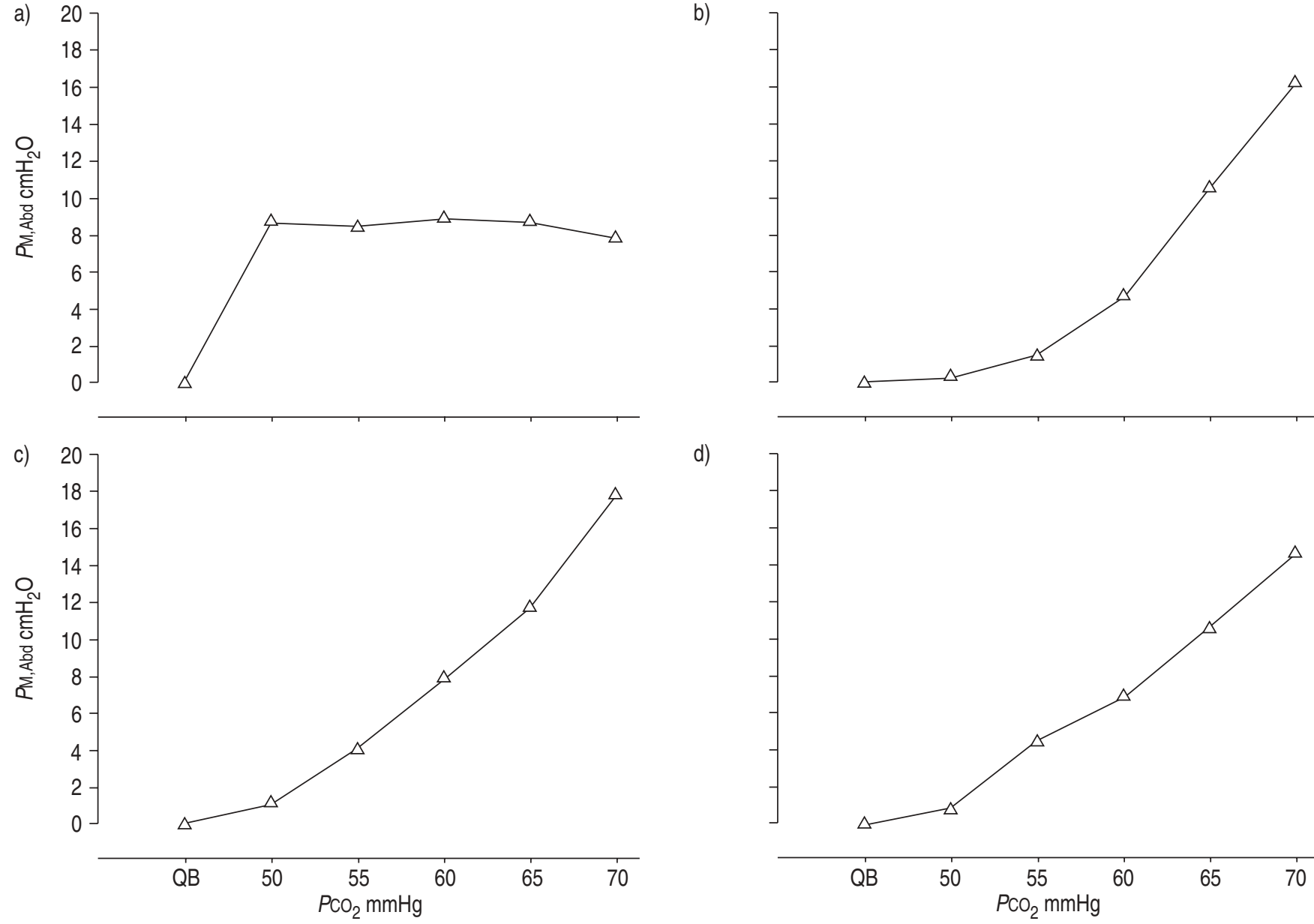

d)

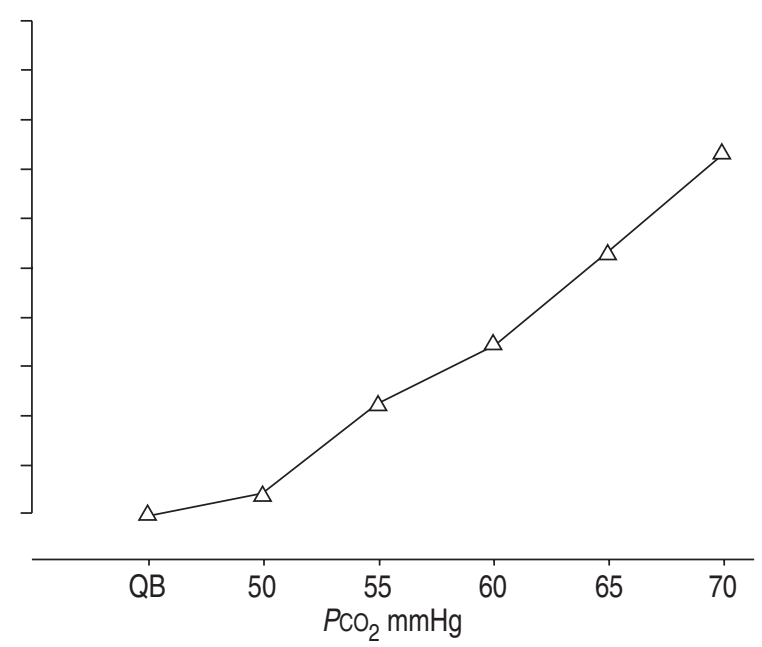

Fig. 5. - Peak abdominal muscle pressure $(P \mathrm{M}, \mathrm{Abd})$ during quiet breathing $(\mathrm{QB})$ and at different expired carbon dioxide tensions $\left(P_{\mathrm{CO}}\right)$ in patients: a) 1 ; b) 3 ; c) 5 ; and d) $6.1 \mathrm{mmHg}=0.133 \mathrm{kPa}$.

respiratory muscle responses control the volumes of the chest wall compartments and whether, and to what extent, the diaphragm and the abdomen take over chest wall expansion during chemically stimulated breathing. Since the landmark paper of RAHN et al. [24], displacement of dynamic pressure/ volume curves away from the relaxation line has been used to quantify respiratory pressure work. The present authors have extended this quantitative method to the study of patients with ankylosing spondylitis.

\section{Discussion of the results}

Chest wall volume changes. The present finding of a gradual decrease in $V$ Abd,EE are in line with results obtained by magnetometry or respiratory inductance plethysmography in healthy subjects $[10,19,25-28]$ and patients with ankylosing spondylitis [4]. The novel finding of the present study, in which a method that neither requires calibration nor depends on the degree of freedom was used [16], was the direct assessment of volume changes in the three chest wall compartments. The present data suggest that the decrease in $V \mathrm{cw}, \mathrm{EE}$ is a basic mechanism for increasing ventilation. Diminishing the $V_{\mathrm{cw}}, \mathrm{EE}$ primarily by decreasing the $V$ Abd,EE may be viewed as a means of utilising the most compliant compartment to minimise the elastic work of moving the chest wall [29]. This qualitative behaviour of chest wall kinematics was operating here in controls as well as in patients.
In line with previous reports on healthy subjects during cycling [8], or walking [9], controls increased their $V_{\mathrm{cw}, \mathrm{EI}}$ entirely via the $V \mathrm{rc}$,EI (see fig 3 ), whereas patients increased their $V$ Abd,EI.

Respiratory muscle recruitment. Respiratory muscle recruitment during hypercapnic stimulation has long been assessed in healthy humans [18, 26-28, 30, 31]. Some of these studies have shown that a decrease in the VAbd,EE optimises diaphragm configuration so that it can generate more pressure [26-28]. A novel finding of the present study is the direct assessment of $P \mathrm{M}, \mathrm{rc}, \mathrm{I}$ and $P \mathrm{M}, \mathrm{rc}, \mathrm{E}, P \mathrm{M}, \mathrm{Abd}$ and pressure production by the diaphragm in patients with ankylosing spondylitis. The compartmental analysis of the volume/ pressure loop proposed contributes to knowledge of the coordinated action of respiratory muscles in these patients. Patients reached a $V^{\prime}$ E comparable to that of controls by using lower $P$ M,rc, I and $P$ M,rc,E and, to a lesser extent, $P$ M,Abd. Nevertheless, diaphragm action was more efficient in patients (fig. 6), as shown by the 2.17 -fold increase in $P$ di swing compared to the 1.4-fold increase in controls. These findings suggest a diaphragm response similar to that observed with bracing in patients with idiopathic scoliosis [32].

Other different response patterns were found between patients and controls. The progressive recruitment of ribcage inspiratory and expiratory muscles was found even at the lowest level of chemical stimulation in controls, but was remarkably lower in patients. Furthermore, as has been 

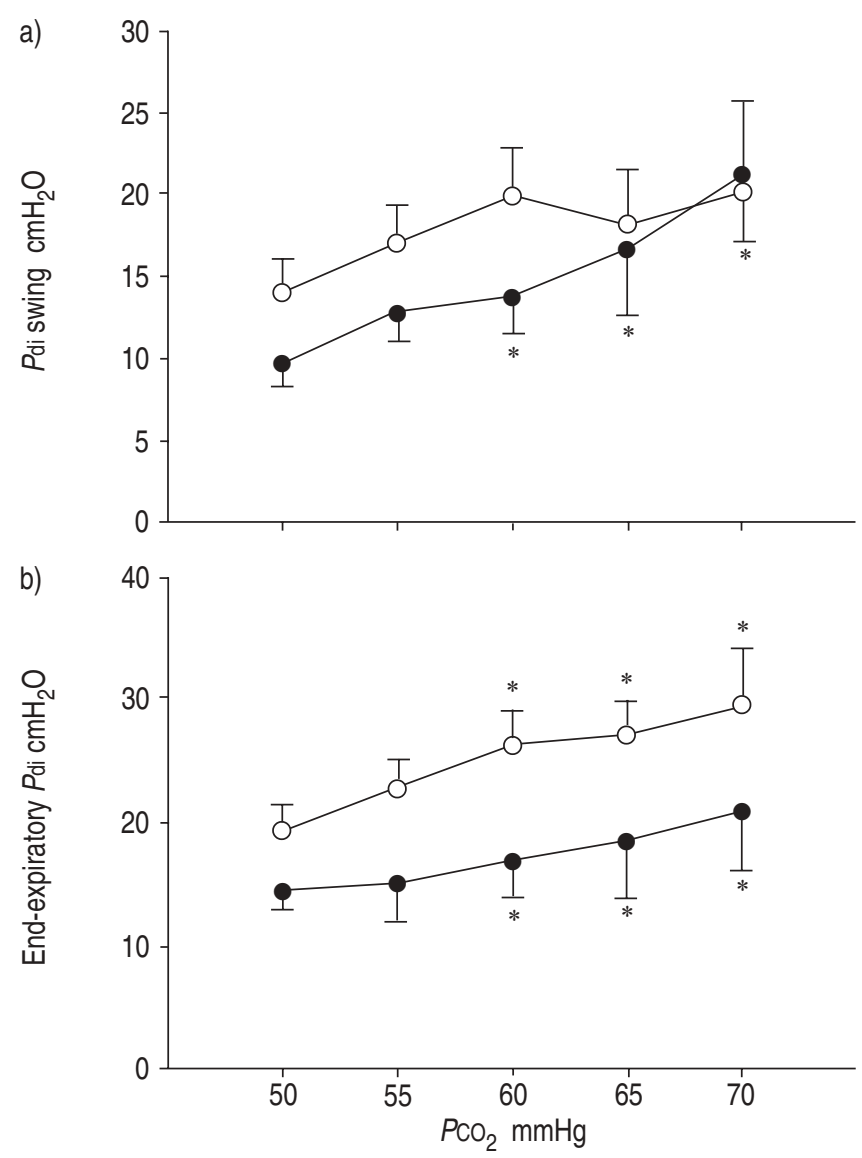

Fig. 6. - Transdiaphgragmatic pressure $\left(P_{\mathrm{di}}\right)$ at different expired carbon dioxide tensions $\left(\mathrm{PCO}_{2}\right)$ : a) inspiratory swing; and b) at endinspiration (๑: patients; $\bigcirc$ : controls). Data are presented as mean \pm SEM. *: $\mathrm{p}<0.05$ versus $P$ di in same group during quiet breathing. $1 \mathrm{mmHg}=$ $0.133 \mathrm{kPa}$.

shown previously $[8,9,11]$, during increased ventilation in healthy subjects, the diaphragm acts mainly as a flow generator as most of its power comes from the velocity of shortening, not $P$ di; the ribcage and abdominal muscles develop the pressure to displace the ribcage and the abdomen, respectively. Consistently, in the present study, $P$ di swings did not change from QB to end-rebreathing (fig. 6), whereas, at a $P \mathrm{CO}_{2}$ of $9.3 \mathrm{kPa}(70 \mathrm{mmHg}), P \mathrm{M}, \mathrm{rc}, \mathrm{I}$ increased $\sim 5$-fold and $P$ M,Abd increased from 0 to $20 \mathrm{cmH}_{2} \mathrm{O}$ in controls. Data in patients were quite different for two reasons. First, in keeping with the observation of a compensatory increase on diaphragm excursion during hyperventilation $[4,6]$, the progressive increase in $P$ di swings indicated the contribution of this muscle to the increased abdominal expansion. Secondly, patients exhibited an outward abdominal displacement ( $V$ Abd,EI) considerably greater during hypercapnia than during QB. Whether this excessive outward displacement during $\mathrm{CO}_{2}$ stimulation shortens the diaphragm to such an extent that it becomes ineffective as a pressure generator remains an unresolved question.

\section{Conclusion}

In summary, by combining pressure measurement with chest wall kinematics, it was shown that the diaphragm/ abdomen compartment plays a prominent role in the production of chest wall tidal volume, regardless of disease severity. An understanding of chest wall dynamics is essential to the individual tailoring of rehabilitation programmes for ankylosing spondylitis patients.

\section{References}

1. Vanderschueren D, Decramer M, Van den Daele P, Dequeker J. Pulmonary function and maximal transrespiratory pressures in ankylosing spondylitis. Ann Rheum Dis 1989; 48: 632-635.

2. Sharp JT, Sweany SK, Henry JP, et al. Lung and thoracic compliances in ankylosing spondylitis. J Lab Clin Med 1964; 63: 254-263.

3. Josenhans WT, Wang CS, Josenhans G, Woodbury JFL. Diaphragmatic contribution to ventilation in patients with ankylosing spondylitis. Respiration 1971; 28: 331-346.

4. Grimby G, Fugl-Meyer AR, Bloomstand A. Partitioning of the contribution of rib cage and abdomen to ventilation in ankylosing spondylitis. Thorax 1974; 29: 179-184.

5. Fisher LR, Cawley MID, Holgate ST. Relation between chest expansion, pulmonary function, and exercise tolerance in patients with ankylosing spondylitis. Ann Rheum Dis 1990; 49: 921-925.

6. Hauge BN. Diaphragmatic movement and spirometric volume in patients with ankylosing spondylitis. Scand J Respir Dis 1973; 54: 38-44.

7. De Troyer A, Sampson M, Sigrist S, Macklem PT. The diaphragm: two muscles. Science 1981; 213: 237-238.

8. Aliverti A, Cala SJ, Duranti R, et al. Human respiratory muscle action and control during exercise. J Appl Physiol 1997; 83: 1256-1269.

9. Sanna A, Bertoli F, Misuri G, et al. Chest wall kinematics and respiratory muscle in walking healthy humans. $J$ Appl Physiol 1999; 87: 938-946.

10. Gorini $\mathrm{M}$, Corrado $\mathrm{A}$, Aito $\mathrm{S}$, et al. Ventilatory and respiratory muscle responses to hypercapnia in patients with paraplegia. Am J Respir Crit Care Med 2000; 162: 203208.

11. Romagnoli I, Gigliotti F, Lanini B, et al. Respiratory muscle co-ordinate activity during hypercapnic rebreathing in healthy man. Eur J Appl Physiol 2004; 91: 525-533.

12. Van der Linden S, Valkenburg HA, Cats A. Evaluation of diagnostic criteria for ankylosing spondylitis. A proposal for modification of the New York criteria. Arthritis Rheum 1984; 27: 361-368.

13. Calin A, Nakache JP, Gueguen A, Zeidler H, Mielants H, Dougados M. Outcome variables in ankylosing spondylitis: evaluation of their relevance and diagnostic capacity. J Rheumatol 1999; 26: 975-979.

14. Scano G, Garcia-Herreros P, Stendardi D, Degre S, De Coster A, Sergysels R. Cardiopulmonary adaptation to exercise in coal miners. Arch Environ Health 1980; 35: 360366.

15. European Community for Coal and Steel. Standardisation of lung function tests. Eur Respir J 1993; 6: Suppl. 16, 1-100.

16. Cala SJ, Kenyon CM, Ferrigno G, et al. Chest wall estimation by optical reflectance motion analysis. $J$ Appl Physiol 1996; 81: 2680-2689.

17. Ward ME, Ward JW, Macklem PT. Analysis of human chest wall motion using a two-compartment rib cage model. $J$ Appl Physiol 1992; 72: 1338-1347.

18. Yan S, Sliwinski P, Gauthier AP, Lichros I, Zakynthinos S, Macklem PT. Effect of global inspiratory muscle fatigue on ventilatory and respiratory muscle responses to $\mathrm{CO}_{2} . \mathrm{J} \mathrm{Appl}$ Physiol 1993; 75: 1371-1377.

19. Yan S, Sliwinski P, Macklem PT. Association of chest wall motion and tidal volume responses during $\mathrm{CO}_{2}$ rebreathing. J Appl Physiol 1996; 81: 1528-1534.

20. Read DJC. A clinical method for assessing the ventilatory response to carbon dioxide. Australas Ann Med 1967; 16: 2032. 
21. Spinelli A, Marconi G, Gorini M, Pizzi A, Scano G. Control of breathing in patients with myasthenia gravis. Am Rev Respir Dis 1992; 145: 1359-1366.

22. Bland JM, Altman DG. Statistical methods for assessing agreement between two methods of clinical measurement Lancet 1986; 346: 307-310.

23. Ward ME, Corbeil C, Gibbon SW, Newman S, Macklem PT. Optimization of respiratory muscle relaxation during mechanical ventilation. Anesthesiology 1988; 69: 29-35.

24. Rahn H, Otis AB, Chadwich LE, Fenn WO. The pressure volume diagram of the thorax and lung. Am J Physiol 1946; 146: $161-178$.

25. Pengelly LD, Tarshis AM, Rebuck AS. Contribution of rib cage and abdomen-diaphragm to tidal volume during $\mathrm{CO}_{2}$ rebreathing. J Appl Physiol 1979; 46: 709-715.

26. Grimby G, Goldman M, Mead J. Respiratory muscle action inferred from rib cage and abdominal V-P partitioning. J Appl Physiol 1976; 41: 739-751.
27. Grassino AE, Derenne JP, Almirall J, Milic Emili J Whitelaw W. Configuration of the chest wall and occlusion pressures in awake humans. $J$ Appl Physiol 1981; 50: 134-142.

28. Henke KJ, Sharrat M, Pegelow D, Dempsey JA. Regulation of end-expiratory lung volume during exercise. $J$ Appl Physiol 1988; 64: 135-146.

29. Konno K, Mead J. Measurement of separate volume changes of rib cage and abdomen during breathing. $J$ Appl Physiol 1967; 22: 402-422.

30. Takasaki Y, Orr D, Popkin J, Xie A, Bradley TD. Effect of hypercapnia and hypoxia on respiratory muscle activation in humans. J Appl Physiol 1989; 67: 1776-1784.

31. Tadashi A, Kusuhara N, Yoshimura N, Tomita T, Easton PA. Differential respiratory activity of four abdominal muscles in humans. J Appl Physiol 1996; 80: 1379-1389.

32. Kennedy JD, Robertson CF, Hudson I, Phelan PD. Effect of bracing on respiratory mechanics in mild idiopathic scoliosis. Thorax 1989; 44: 548-553. 